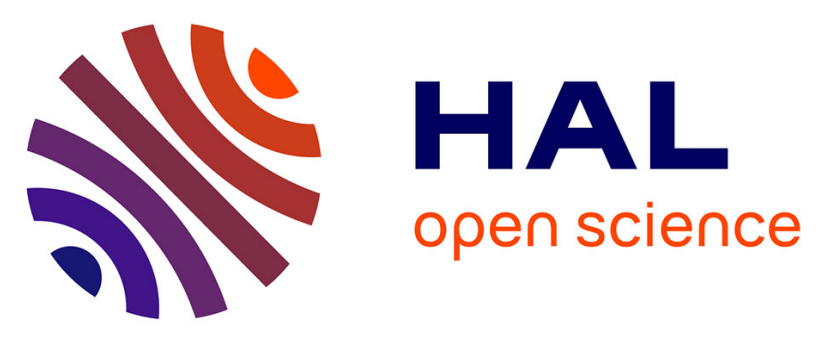

\title{
Hydrothermal Carbon from Biomass: Structural Differences between Hydrothermal and Pyrolyzed Carbons via 13C Solid State NMR
}

Camillo Falco, Fernando Caballero Perez, Florence Babonneau, Christel Gervais, Guillaume Laurent, Maria-Magdalena Titirici, Niki Baccile

\section{To cite this version:}

Camillo Falco, Fernando Caballero Perez, Florence Babonneau, Christel Gervais, Guillaume Laurent, et al.. Hydrothermal Carbon from Biomass: Structural Differences between Hydrothermal and Pyrolyzed Carbons via 13C Solid State NMR. Langmuir, 2011, 27 (23), pp.14460-14471. 10.1021/la202361p . hal-01457064

\section{HAL Id: hal-01457064 https://hal.sorbonne-universite.fr/hal-01457064}

Submitted on 6 Feb 2017

HAL is a multi-disciplinary open access archive for the deposit and dissemination of scientific research documents, whether they are published or not. The documents may come from teaching and research institutions in France or abroad, or from public or private research centers.
L'archive ouverte pluridisciplinaire HAL, est destinée au dépôt et à la diffusion de documents scientifiques de niveau recherche, publiés ou non, émanant des établissements d'enseignement et de recherche français ou étrangers, des laboratoires publics ou privés. 
IMPORTANT NOTE: Please be aware that slight modifications occurring after Proof correction may occur between this version of the manuscript and the version on the Publisher's website

\section{Hydrothermal Carbon from Biomass. Structural}

\section{Differences between Hydrothermal and Pyrolyzed}

\section{Carbons via ${ }^{13} \mathrm{C}$ Solid State NMR}

Camillo Falco, ${ }^{4}$ Fernando Perez Caballero, ${ }^{4}$ Florence Babonneau, ${ }^{1,2,3}$ Christel Gervais, ${ }^{1,2,3}$ Guillaume Laurent, ${ }^{1,2,3}$ Maria-Magdalena Tititici, ${ }^{4}$ Niki Baccile ${ }^{1,2,3}$ *

1-UPMC Univ Paris 06, UMR 7574, Chimie de la Matière Condensée de Paris, F-75005, Paris, France

2- CNRS, UMR 7574, Chimie de la Matière Condensée de Paris, F-75005, Paris, France 3 - Collège de France, UMR 7574, Chimie de la Matière Condensée de Paris, F-75005, Paris, France

4- Max-Planck Institute for Colloids, Research Campus Golm, D-14424 Potsdam, Germany

RECEIVED DATE (to be automatically inserted after your manuscript is accepted if required according to the journal that you are submitting your paper to)

CORRESPONDING AUTHOR FOOTNOTE

* Corresponding Author. E-mail: niki.baccile@upmc.fr, Fax: +33144271544

+ UPMC Univ Paris 06, Laboratoire de Chimie de la Matière Condensée de Paris, 4 place Jussieu, 


\section{ABSTRACT}

The objective of this paper is to better describe the structure of the hydrothermal carbon (HTC) process and put it in relationship with the more classical pyrolytic carbons. Indeed, despite the low energetic impact and the number of applications described so far for HTC, very little is known about the structure, reaction mechanism and the way these materials relate to coals. Are HTC and calcination processes equivalent? Are the structures of the processed materials related to each other in any way? Which is the extent of polyaromatic hydrocarbons (PAH) inside HTC? In this work, the effect of hydrothermal treatment and pyrolysis are compared on glucose, a good model carbohydrate; a detailed Single-Quantum Double-Quantum (SQ-DQ) solid state ${ }^{13} \mathrm{C}$ NMR study of the HTC and calcined HTC is used to interpret the spectral region corresponding to the signal of furanic and arene groups. These data are compared to the spectroscopic signatures of calcined glucose, starch and xylose. A semi-quantitative analysis of the ${ }^{13} \mathrm{C}$ NMR spectra provides an estimation of the furanic-to-arene ratio which varies from 1:1 to 4:1 according to the processing conditions and carbohydrate employed. In addition, we formulate some hypothesis, validated by DFT (Density Functional Theory) modeling associated with ${ }^{13} \mathrm{C}$ NMR chemical shifts calculations, about the possible furan-rich structural intermediates that occur in the coalification process leading to condensed polyaromatic structures. In combination with a broad parallel study on the HTC processing conditions effect on glucose, cellulose and raw biomass (Falco et al., Green Chem., 2011, DOI: 10.1039/C1GC15742F), we propose a broad reaction scheme and in which we show that, through HTC, it is possible to tune the furan-to-arene ratio composing the aromatic core of the produced HTC carbons, which is not possible if calcination is used alone, in the temperature range below $350^{\circ} \mathrm{C}$. 
KEYWORDS.

\section{Introduction}

In the past 10 years, hydrothermal carbonization (HTC) of biomass has gained an increasing interest in the field of material science. This process, which is known since early 1900 to make synthetic coal at lower temperature, was recently rediscovered for the synthesis of functional carbon-based materials with applications in important fields such as energy storage, adsorption and separation science, catalysis, biomedicine and many others. ${ }^{1,2}$ The most interesting point of this approach is undoubtedly the perspective of processing waste biomass into valuable carbonaceous materials, although the main research work so far has been done using pure carbohydrates, which constitute the simplest building block of the saccharide components of raw biomass. One of the main reasons for that is the fact that the chemical reactions involved in the hydrothermal process are complex and much has still to be done to clarify the exact mechanisms of char formation. It was recently pointed out that most studies on the hydrothermal treatment of biomass (saccharides, cellulose, lignins, etc..) were mainly focused at understanding the initial steps of the reaction mechanisms: hydrolysis, dehydration, decarboxylation, rather than polymerization and aromatization $^{1 \mathrm{~d}}$. The reason for this depends on the fact that little is known on the final structure of the carbonaceous matter, which prevents valuable models accounting for the late stages of the reaction. Several characterization techniques like FT-IR ${ }^{2 b, 3}, \mathrm{XPS}^{4}, \mathrm{XRD}$ and solid state ${ }^{13} \mathrm{C}_{\mathrm{NMR}}{ }^{\mathrm{b}}$ ${ }^{, 5}$ have been used to identify the carbonaceous structure but a clear agreement is not found yet.

Three main structural models are available in literature: the first one, proposed on the basis of FT-IR, Raman and XPS spectroscopies, considers the carbonaceous scaffold as being composed of "small clusters of condensed benzene rings that form stable groups with oxygen in the core" 6 (Scheme 1a); the second one, based on advanced solid state ${ }^{13} \mathrm{C}$ NMR experiments, highlights the 
importance of furans rather than arene rings in the carbonaceous scaffold ${ }^{7}$ (Scheme 1b). A third one, in which a few furan units are outnumbered by polyaromatic structures, was also proposed on the basis of FT-IR and Raman spectroscopies ${ }^{8}$ (Scheme 1c). Models 1 and 2 are quite in contrast with each other while model 3 can be looked at as a hybrid intermediate. In any case, we believe that a general structure able to fulfill all experimental evidences found by several authors has not been proposed, yet.
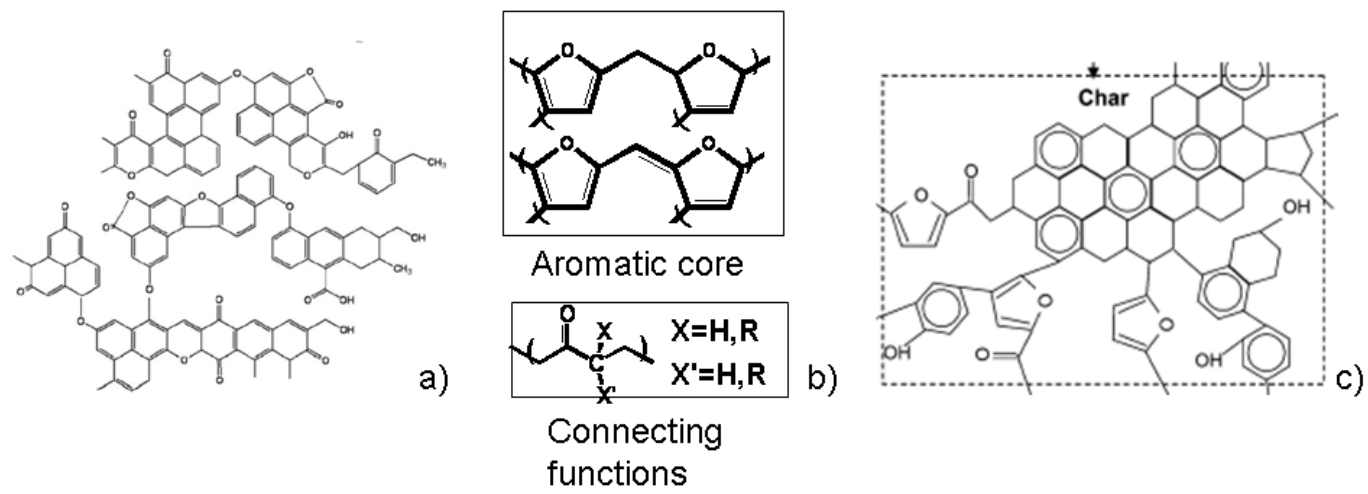

Scheme 1 - Existing structural models proposed for HTC. a) Adapted from Ref. 6a; b) Adapted from Ref. 7b; c) Adapted from Ref. 8.

To study these specific materials, whose structure is amorphous and whose spectroscopic signature relatively complex, we believe that solid state NMR is definitely the best candidate technique as it provides better spectral resolution with respect to other techniques like FT-IR or XPS. Other great advantages of NMR are: - the possibility of using selective pulse sequences to identify and separate chemical species without ambiguity, as we have previously shown for hydrothermal carbons obtained from glucose. ${ }^{7 b}$ - Better quantification, with respect to FT-IR and XPS, possible with ${ }^{13} \mathrm{C}$ NMR due to the spectral resolution. - The combination of isotopic enrichment and single-quantum double-quantum (SQ-DQ) ${ }^{13} \mathrm{C}$ correlation experiments provides the best way possible to study the local structure of the carbonaceous material and probe direct carboncarbon bonds. ${ }^{9}$

Even if many features of the structure of hydrothermal carbon (HTC) still needs clarification, a lot of work already exists in the domain of coals, woods, lignins, cellulose and their charred 
derivatives at various temperatures. Historically, the structural study of charred biomass has been a long-time task in which mainly FT-IR and solid state NMR have been employed as valuable characterization techniques.

Char is an amorphous material constituted of an intrinsic mixture of aliphatic and aromatic carbons whose identification and mechanism of formation constituted a matter of interest. Early FTIR studies can be traced back to the $60 \mathrm{~s}^{10}$, while solid state ${ }^{13} \mathrm{C}$ NMR started to be employed much later. ${ }^{11,12}$ Use of NMR was necessary to complement infrared data and more up-to-date models of the early stages of the carbonization process could then be proposed. ${ }^{13}$ In the beginning, natural coals and lignins from different geographical environments were studied with ${ }^{13} \mathrm{C}$ CP-MAS NMR, which was used to attribute the signals coming from aromatic and aliphatic species and study their polarization dynamics ${ }^{14}$. These materials show an extended aromatic and phenolic network. In 1994, Pastorova et al. presented one of the first studies where ${ }^{13} \mathrm{C}$ NMR was combined with GCMS and FT-IR to elucidate the structure of char obtained from pyrolyzing cellulose between 250$400^{\circ} \mathrm{C}$ for 150 minutes. They showed that cellulose keeps its initial structure up to $250^{\circ} \mathrm{C}$ while major chemical modifications occur at $270^{\circ} \mathrm{C}$; both phenolic and furanyl groups were detected as volatile compounds.

The idea that the structure of char from cellulose or other biopolymers (pectins, wood) is mainly constituted of an aromatic motif in the presence of furanoic compounds connected via aliphatic bridges is generally accepted. ${ }^{15,16}$ For instance, Zhang et al. ${ }^{16}$ suggested the presence of furfuryl motifs in char obtained from pyrolyzed starch. Nevertheless, in most studies, probably due to the lack of a clear-cut proof, the structures were rather interpreted as being composed of polyaromatic hydrocarbons, ${ }^{13,14,17,18,19,20}$ as in lignins or coal. ${ }^{12,21,22}$

The mechanism of formation of char and the fate of the polysaccharide network at medium/high pyrolysis temperatures (that is less than $500^{\circ} \mathrm{C}$ ) has also attracted much attention and the elucidation was mainly possible via a fine NMR study. Wooten at al. ${ }^{13}$ have shown that, after 30 minutes at $300^{\circ} \mathrm{C}$, cellulose undergoes depolymerization to form an "intermediate cellulose" 
product, which then transforms into a "final carbohydrate" (FC) before aromatization and which was associated with large amount of oligo and polysaccharides.

The hydrothermal treatment of mono or polysaccharides provides carbonaceous materials whose NMR spectroscopic signature has been reported in ref. 7. A quick interpretation of ${ }^{13} \mathrm{C}$ NMR data, corroborated with FT-IR, XPS and Raman data, ${ }^{6 a, 8}$ may induce a description of the carbonaceous structure as being composed of extended aromatic network with randomly distributed oxygen functionalities. In reality, a detailed NMR analysis based on cross polarization and singlequantum double-quantum (SQ-DQ) excitations experiments, ${ }^{7 b}$ demonstrate the existence of a furanic network rather than a simple polyaromatic hydrocarbon (PAH) structure containing $\mathrm{OH}$ substitutions. Nevertheless, the ${ }^{13} \mathrm{C}$ NMR response of hydrothermal carbons is not always

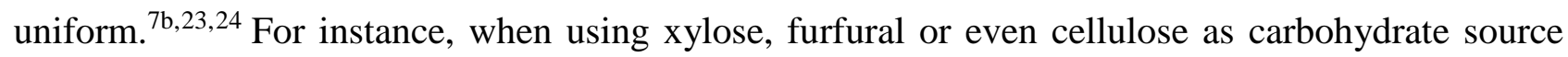
under similar conditions, the NMR spectrum can be dominated by an intense signal centered at about 127 ppm suggesting a predominant polyaromatic structure, as normally observed for their calcined derivatives under inert atmosphere at $\mathrm{T}>300^{\circ} \mathrm{C}$. When it comes to the study of the HTC structures obtained from waste biomass, an interesting ${ }^{13} \mathrm{C}$ MAS NMR work was recently published on the influence of processing and pre-treatment conditions on the aromatic component of the hydrothermally-treated $\operatorname{char}^{25}$.

In this paper, we aim at clarifying the general effect of hydrothermal treatment on glucose, cellulose and other biomass-derived carbohydrate-based compounds. In particular we want to highlight the effect of processing conditions on the structure and correlate the structure of hydrothermal carbons with the one of char. One way of achieving our goal is to provide a quick method to evaluate the relative furan-to-arene ratio in both hydrothermal and pyrolized carbons. The amount of condensed arene groups with respect to furans is a very important piece of information: 1) it allows comparing hydrothermal carbons with respect to pyrolized carbons and helps classifying it either as a polyfuran resin or char; 2) it allows understanding the relationship 
between HTC processing conditions and the final material structure; 3) it helps understanding the complex, still unknown, process of formation of these materials.

Our approach consists of making a detailed structural comparison among carbonaceous materials obtained from different techniques and containing different amount of polyaromatic structures: HTC, calcined HTC, and directly calcined carbohydrates. We use here a combination of advanced solid state ${ }^{13} \mathrm{C}$ NMR techniques, whose importance in the structural resolution of coals and charred biomass has been largely established. ${ }^{12,13,14,16,17,18,26,27}$ This approach allows us to propose few furan-based structural units which may play an important role in the formation of polyaromatic structures. DFT (Density Functional Theory) calculations and $a b$-initio calculations of

${ }^{13} \mathrm{C}$ chemical shifts will help us validating the proposed structural building block and, finally, after interpreting a wide range of NMR data collected on both HTC and pyrolyzed carbohydrates, from glucose to cellulose, we propose a general scheme of possible reaction pathways that put in relationship the HTC process and material structure. That also includes the effect of both hydrothermal and calcination treatment on the furan-to-arene ratio.

\section{Experimental Section}

All carbohydrates used in this study were purchased from Aldrich and used as received. Unless otherwise stated, hydrothermal synthesis was done in water at $180^{\circ} \mathrm{C}$ during 12 hours using a Teflon-lined autoclave; more detailed descriptions of the synthesis of hydrothermal carbons are given elsewehere. ", 23,24,28 The hydrothermally-treated sample is labeled “HTC-glucose”.

Pyrolysis was done under nitrogen atmosphere at various temperatures which were selected according to three different structural states of the carbonization process. It has been shown that between 270 and $400^{\circ} \mathrm{C}^{11,17,29}$ major structural changes occur in the carbohydrate structure but part of the aliphatic and oxygen functionalities are kept. Additionally, TGA has shown that mass loss occurs in this temperature range at low heating rates $\left(<5^{\circ} \mathrm{C} / \mathrm{min}\right) .{ }^{30}$ At $\mathrm{T}>500^{\circ} \mathrm{C}$, functions like carboxylic acids, ketones and aliphatics are generally gone but phenolic groups are kept. At T> 
$600 / 700^{\circ} \mathrm{C}$. the material is entirely composed of polyaromatic hydrocarbons. According to these considerations, two different sets of samples were treated: a) HTC-derived materials named as follows, HTC-glucose $\left(\Delta 350^{\circ} \mathrm{C}\right)$, HTC-glucose $\left(\Delta 550^{\circ} \mathrm{C}\right)$, HTC-glucose $\left(\Delta 750^{\circ} \mathrm{C}\right)$ were first prepared at $\mathrm{T}=180^{\circ} \mathrm{C}$ for $\mathrm{t}=12 \mathrm{~h}$ and then, after recovery and drying, they were calcined at $\mathrm{T}=350^{\circ} \mathrm{C}, 550^{\circ} \mathrm{C}$ and $750^{\circ} \mathrm{C}$ (heating rate $=1^{\circ} \mathrm{C} / \mathrm{min} ; \mathrm{t}=6 \mathrm{~h}$ ); b) carbohydrates were directly pyrolyzed at $\mathrm{T}=350^{\circ} \mathrm{C}$ (heating rate $\left.=1^{\circ} \mathrm{C} / \mathrm{min} ; \mathrm{t}=6 \mathrm{~h}\right)$ and named as follows: glucose $\left(\Delta 350^{\circ} \mathrm{C}\right), \operatorname{starch}\left(\Delta 350^{\circ} \mathrm{C}\right)$, xylose $\left(\Delta 350^{\circ} \mathrm{C}\right)$.

${ }^{1} \mathrm{H}$ and ${ }^{13} \mathrm{C}$ solid-state Magic Angle Spinning (MAS) NMR experiments have been acquired on a Bruker Avance $300 \mathrm{MHz}$ (7 T) spectrometer using $4 \mathrm{~mm}$ zirconia rotors spinning at a MAS frequency of $v_{\text {MAS }}=14 \mathrm{kHz} \cdot{ }^{1} \mathrm{H}$ and ${ }^{13} \mathrm{C}$ chemical shifts were referenced relative to tetramethylsilane (TMS; $\delta=0 \mathrm{ppm})$.

Single pulse MAS experiments: pulse lengths ( $90^{\circ}$ flip angle) for ${ }^{13} \mathrm{C}$ was $3.15 \mu$ s and the optimum recycle delays was $30 \mathrm{~s}$. Two-pulse phase-modulated (TPPM) proton decoupling ${ }^{31}$ was applied during ${ }^{13} \mathrm{C}$ acquisition $(80 \mathrm{kHz}$ ). Number of transients was 64 for HTC-glucose, 8 for HTCglucose $\left(\Delta 350^{\circ} \mathrm{C}\right), 8$ for HTC-glucose $\left(\Delta 550^{\circ} \mathrm{C}\right)$ and 32 for HTC-glucose $\left(\Delta 750^{\circ} \mathrm{C}\right)$.

Cross-Polarization (CP) MAS experiments: recycle delay for all CP experiments was $3 \mathrm{~s}$ and TPPM decoupling was applied during signal acquisition. Cross-polarization transfers were performed using adiabatic tangential ramps ${ }^{32,33}$ and the $\mathrm{CP}$ contact time was $\mathrm{t}_{\mathrm{CP}}=3 \mathrm{~ms}$. Number of transient was 64 for all isotopically-enriched samples and 2048 for non-enriched ones. All FIDs were subjected to an exponential multiplication (EM) function with a Line Broadening value of LB $=50 \mathrm{~Hz}$ prior Fourier transform.

Single-Pulse and CP experiments have been decomposed with DMFIT software (2009 version). ${ }^{34}$ Integration values should be considered with at least a $10 \%$ error coming from a trial and error methodology used in the fitting procedure. The peak selected for integration have a fully Gaussian lineshape and they were chosen from our previous publication. ${ }^{7 \mathrm{~b}}$ The only fitting parameter allowed 
to vary is the peak intensity while all others (linewidth, position and Gaussian/Lorentzian ratio) are kept constant.

Non-Quaternary Suppression (NQS) experiments ${ }^{35}$ have been employed to recover the signal of quaternary carbon groups. The pulse sequence is CP-filtered ( $\left.\mathrm{t}_{\mathrm{CP}}=3 \mathrm{~ms}\right)$, synchronized with MAS (14 kHz) and refocused using a $180^{\circ}$ pulse. The dephasing delay is set to $50 \mu$ s (one rotor period).

CP-MAS ${ }^{13} \mathrm{C}$ homonuclear Single-Quantum Double-Quantum (SQ-DQ) correlation experiments have been recorded at a spinning frequency of $14 \mathrm{kHz}$. All the necessary details were given in ref. 7b.

Elemental chemical analysis (C, N, O, S, H) was performed on a Elementar Vario Micro Cube. Structural models were obtained with the VASP (Vienna Ab-initio Simulation Package) 4.6 code ${ }^{36}$ based on the Kohn-Sham Density Functional Theory (DFT) and using a periodic and plane-wave pseudopotential approach. The integral over the first Brillouin zone are performed using a Monkhorst-Pack $1 \times 1 \times 1$ k-point grid ${ }^{37}$. The electron-ion interaction was described by the projector augmented-wave (PAW) method ${ }^{38}$. Atomic positions were first relaxed using ab-initio molecular dynamics (MD) at constant temperature (300 K). The time step was set at 2.5 fs and the geometries were sampled up to 5 ps to have a reliable image of the equilibrium geometry at $300 \mathrm{~K}$ using a micro canonical ensemble. Tritium mass was set for all protons. Using H3 for hydrogen is a standard procedure in $a b$ initio MD to avoid too large displacements of the hydrogen atoms when large time steps are used. Increasing the mass of the atoms helps to avoid destroying the molecular structure. Since every step is very costly in this type of calculations, large time steps are needed in order to obtain a reasonable sampling time. Secondly, an energetically favourable geometry was picked from the MD results and optimized at $0 \mathrm{~K}$ with a $300 \mathrm{eV}$ energy cutoff.

The NMR parameters were calculated within Kohn-Sham DFT using the QUANTUM-ESPRESSO $\operatorname{code}^{39,40}$ in which the GIPAW method ${ }^{41}$ was implemented, keeping the atomic positions and cell constants equal to the values previously calculated with VASP. Details about the computation of the isotropic chemical shifts for ${ }^{1} \mathrm{H}$ and ${ }^{13} \mathrm{C}$ are reported elsewhere. ${ }^{42,43}$ 


\section{Results and discussion}

Detailed peak attribution through ${ }^{13} \mathrm{C}$ solid state $N M R$. We have already pointed out in an earlier study that the structure of HTC from various carbohydrate sources (mono or polysaccharides like sucrose, galactose, amylopectin, etc...) is very similar ${ }^{7 a}$ and its chemical environment is composed of furan-rich structures $^{\text {tb }}$. We have also shown that hydromethylfurfural, which is largely produced from the dehydration of hexoses, ${ }^{44}$ is the main precursor of the carbonaceous scaffold. In contrast to what one would normally expect to find as main component of charred materials, that is an arenerich core, the HTC process seems to tend towards the production of furan-rich materials. Nevertheless, in some cases (for instance when xylose is used as carbohydrate precursor ${ }^{7 a}$ ) the final HTC structure presents a strong spectroscopic signature due to condensed arene rings. To better understand the HTC material structure, we decided to compare three sets of materials: the HTC obtained from glucose; its pyrolyzed form and the pyrolyzed glucose itself. Indeed, glucose is a very good model sample for several reasons: - under HTC, it provides both furan-rich and arenerich materials; ${ }^{49}$ - both its HTC and pyrolysis derivatives have comparable structures with respect to many different carbohydrates treated under the same conditions (see ref 7a and data below); Moreover, ${ }^{13} \mathrm{C}$ isotopic enrichment is possible and relatively inexpensive.

Table 1 - Elemental analysis (carbon, hydrogen) for hydrothermally-derived and pyrolized samples. Values are given in wt\%. * Calculated using a depletion method after $\mathrm{C}$ and $\mathrm{H}$ values. $\mathrm{O} / \mathrm{C}$ and $\mathrm{H} / \mathrm{C}$ are given in molar ratio.

\begin{tabular}{cccccc} 
Sample & $\mathbf{C}$ & $\mathbf{H}$ & $\mathbf{O}^{*}$ & $\mathbf{O} / \mathbf{C}$ & $\mathbf{H} / \mathbf{C}$ \\
\hline HTC-glucose & 64.47 & 4.69 & 30.84 & 0.36 & 0.87 \\
HTC-glucose $\left(\Delta 350^{\circ} \mathrm{C}\right)$ & 66.95 & 4.03 & 29.02 & 0.32 & 0.72 \\
HTC-glucose $\left(\Delta 550^{\circ} \mathrm{C}\right)$ & 84.66 & 2.83 & 12.51 & 0.11 & 0.40 \\
HTC-glucose $\left(\Delta 750^{\circ} \mathrm{C}\right)$ & 85.29 & 1.04 & 13.67 & 0.12 & 0.14 \\
Glucose $\left(\Delta 350^{\circ} \mathrm{C}\right)$ & 59.18 & 4.96 & 35.86 & 0.45 & 1.01 \\
Glucose $\left(\Delta 750^{\circ} \mathrm{C}\right)$ & 94.02 & 0.92 & 5.06 & 0.04 & 0.12 \\
Starch $\left(\Delta 350^{\circ} \mathrm{C}\right)$ & 63.51 & 4.46 & 32.03 & 0.38 & 0.84
\end{tabular}

First of all, in order to enhance the signal-to-noise ratio, we prepared a ${ }^{13} \mathrm{C}$-rich glucose-derived HTC sample, our reference material (Figure 1a). We know from a previous work ${ }^{7 b}$ that the core of 
this material is mainly composed of a poly-furanic network, whose related NMR signatures are indicated in Figure 1a with two main resonances at 110 and $150 \mathrm{ppm}$. This product was then processed under nitrogen at $\mathrm{T}=350^{\circ} \mathrm{C}$, and is referred to as HTC-glucose $\left(\Delta 350^{\circ} \mathrm{C}\right)$. The ${ }^{13} \mathrm{C}$ MAS NMR and their elemental composition are shown in Figure 1b and Table 1. The elemental analysis for HTC-glucose $\left(\Delta 350^{\circ} \mathrm{C}\right)$ are comparable to HTC-glucose, which means that pyrolysis did not affect much the chemical composition of the original material; however, its ${ }^{13} \mathrm{C}$ NMR spectrum (Figure 1b), starts to change in the 150-100 ppm region. These modifications are clearly evidenced at the $\mathrm{T}=550^{\circ} \mathrm{C}$ with the presence of a dominant peak at $127 \mathrm{ppm}$.

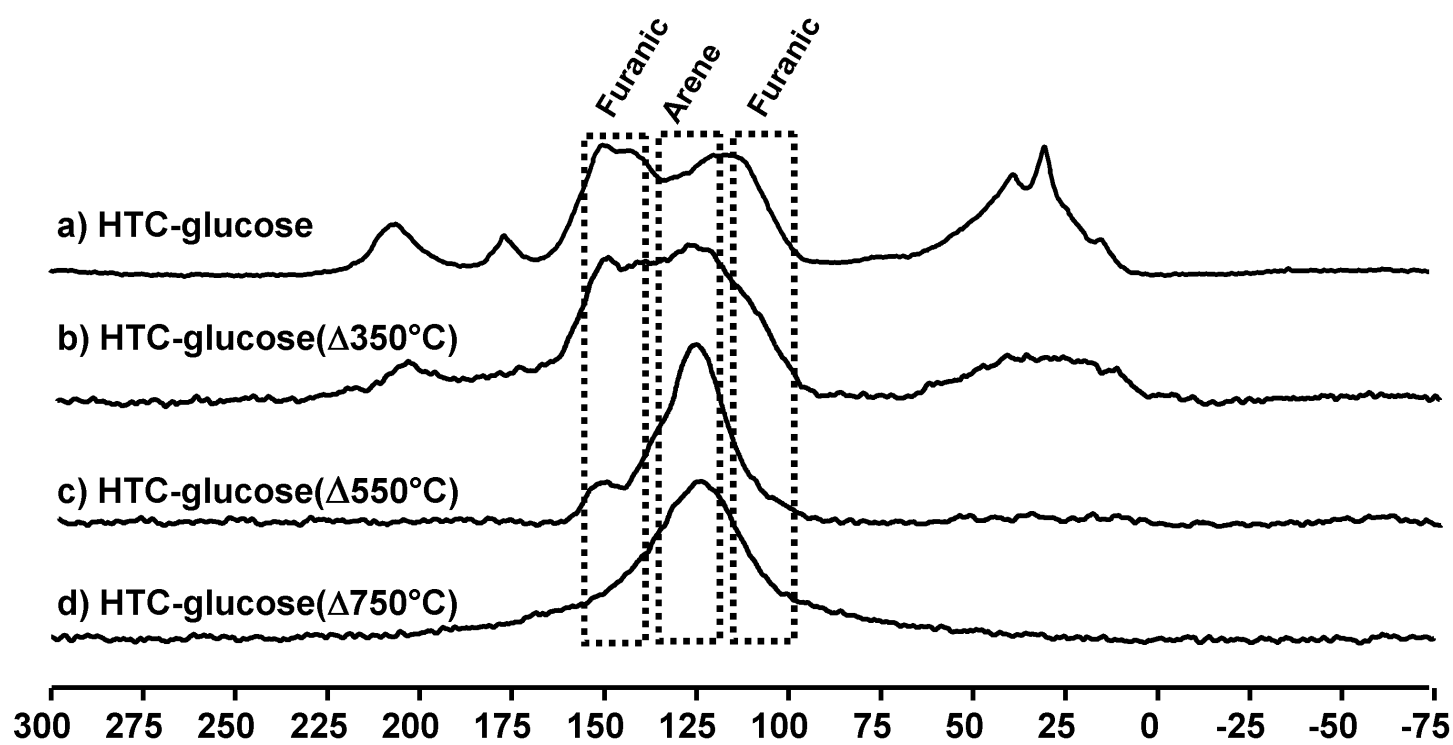

Figure 1 - Single-pulse MAS ${ }^{13} \mathrm{C}$ NMR experiments performed on the sample "HTC-glucose" as a function of calcination temperature. All samples were obtained from a ${ }^{13} \mathrm{C}$-rich glucose source.

The shoulder in the 110-100 ppm region has disappeared (Figure 1c), indicating that furans are consumed in the carbonization process, while the one at $151 \mathrm{ppm}$ is still detected, but with a much lower intensity. These results show that aromatization proceeds further on upon temperature increase. Loss in oxygen (final value, $\mathrm{O}=12.5 \mathrm{w} \%$ ) for HTC-glucose $\left(\Delta 550^{\circ} \mathrm{C}\right.$ ) (Table 1 ) sample strengthens this hypothesis. At even higher pyrolysis temperatures, $\mathrm{T}=750^{\circ} \mathrm{C}$, the $\mathrm{HTC}$-based material, HTC-glucose $\left(\Delta 750^{\circ} \mathrm{C}\right)$, shows an intense peak centered at $125 \mathrm{ppm}$ (Figure $1 \mathrm{~d}$ ). This NMR signature at high temperature is quite common ${ }^{16,17,19}$. 
The SQ-DQ carbon-carbon maps of HTC-glucose, HTC-glucose $\left(\Delta 350^{\circ} \mathrm{C}\right)$, HTCglucose $\left(\Delta 550^{\circ} \mathrm{C}\right)$ and HTC-glucose $\left(\Delta 750^{\circ} \mathrm{C}\right)$ are shown in Figure 2(a-d). We have previously ${ }^{7 \mathrm{~b}}$ studied the whole ${ }^{13} \mathrm{C}$ spectroscopic range of HTC-glucose and tried to give a broad description of the possible chemical groups which are part of the structure of this material. Here, we just focus on a more detailed analysis of the central 150-100 ppm region, which, for glucose undergoing simple hydrothermal treatment at $\mathrm{T}=180^{\circ} \mathrm{C}$ (Figure 2a), is characterized, as mentioned previously, by two symmetric resonances at 151 and 110 ppm identifying a furan-rich core. The cross peak at $118 \mathrm{ppm}$ lies on the diagonal indicating a specific homocorrelation between two non-protonated $\mathrm{sp}^{2}$ carbons, as shown in ref. 7b by mean of cross-polarization experiments at variable contact times and confirmed in this study by Non-Quaternary Suppression (NQS) Cross-Polarization experiments shown in SuppMat Figure 1. In the same work, we attributed it to a $\beta-\beta$ bond between two furan units and responsible of the cross-linking of the polyfuran scaffold (Figure 2e). The on-diagonal cross-peak at 143 ppm also deserves a special attention as it outlines a $\mathrm{O}-\underline{C}=\mathrm{C}$ - site. This resonance is still matter of discussion. In the domain of lignins, for instance, the resonance in the $140 \mathrm{ppm}$ region is generally attributed to free phenolic units ${ }^{22}$ or acetylated $\mathrm{OH}$ groups ${ }^{45}$ while in the domain of furanic resins, it is generally attributed to a non-substituted, protonated, $\alpha$-carbon of the furan ring. ${ }^{46,47}$ Despite these attributions, we proposed a new attribution based on our own results and on strong experimental evidences. In the case of HTC-glucose, the resonance at 143 ppm presents four main features: 1) its corresponding cross-peak on the SQ-DQ experiments lies on the diagonal, indicating a homocorrelation of the corresponding resonance; 2) according to cross-polarization experiments at variable contact times, and NQS experiments shown in SuppMatFig.1, this resonance identifies a non-protonated carbon atom; 3) no correlations with aliphatic or carbonyls can be traced for this resonance (see Figure 6 in Ref. 7b); 4) the 143-118 ppm cross-peak, identifying a specific intra-furan correlation, can be clearly identified in Figure 2a despite the poor resolution in this spectroscopic region. To account for these spectroscopic results, we assigned this 
resonance to two furanic units directly connected via one of their $\alpha$-carbons. ${ }^{7 b}$ These data combined together help us drawing one possible basic furanic unit, shown in Figure 2e.

When HTC-glucose is calcined at $350^{\circ} \mathrm{C}$ under nitrogen, the material's chemical composition is almost not affected at all (Table 1), suggesting that internal structural rearrangements occur instead of loss of matter. This is also confirmed by the ${ }^{13} \mathrm{C}-{ }^{13} \mathrm{C}$ SQ-DQ NMR experiment presented in Figure 2b. Interestingly, the 2D map does not seem to be highly affected by the temperature treatment of the material in terms of cross-peak shape and symmetry; nevertheless, a close look shows some interesting and very important changes: 1) the peak at 127 ppm, characteristic of condensed benzene rings, becomes more relevant and its corresponding ondiagonal cross peak is now clearly detected in the central region of the SQ-DQ map; 2) the ondiagonal cross-peak at 118 ppm, which still identifies a non-protonated carbon as also confirmed by 1D NQS experiments shown in SuppMatFig2, is now barely detected; 3) the 151-110 ppm crosspeak is still dominant; 4) the 143 ppm resonance still shows an on-diagonal cross-peak; 5) the 143118 ppm resonance is not detected anymore.

These spectroscopic evidences suggest three possible scenarios in terms of chemical changes for the HTC material after calcination at $350^{\circ} \mathrm{C}$.

Hypothesis 1. The fraction of polyaromatic hydrocarbons (PAH) (Figure 2f), related to the peak at 127 ppm, increases with respect to furan-based structures and in particular with respect to the one shown in Figure 2e. The drawbacks of this hypothesis are manifold. - PAH must contain enough oxygen to keep the $\mathrm{O} / \mathrm{C}$ ratio almost unchanged when passing from $\mathrm{HTC}$-glucose $(\mathrm{O} / \mathrm{C}=0.36)$ to HTC-glucose $\left(\Delta 350^{\circ} \mathrm{C}\right)(\mathrm{O} / \mathrm{C}=0.32)$, that is, the aromatic core cannot be too extended. - The offdiagonal 151-110 ppm cross peak is still highly symmetric, it dominates the SQ-DQ map and its shape does not seem to vary at all between the two samples. This suggests that the furanic groups are still largely part of the material. - The off-diagonal 143-118 ppm and the on-diagonal 118 ppm cross peaks are not detected anymore, while the on-diagonal 143 ppm cross-peak is still largely part of the SQ-DQ map. This last remark implies that the intensities of peaks related to structure in 
Figure 2e do not seem to reduce in a homogeneous way, which one would expect in case of a “dilution effect”.

Hypothesis 2. The structure given in Figure 2e undergoes internal rearrangement to give a new unit containing an inner aromatic ring, as proposed in Figure $2 \mathrm{~g}$. This new structure has the advantage of satisfying all NMR data shown in Figure 2b except for the direct detection of the 143-127 ppm cross-peak. At the moment, we are not able to unequivocally highlight this specific resonance.

Hypothesis 3. A combination of both hypothesis 1 and 2, where dilution effects and low resolution do not allow a clear-cut attribution of all resonances. The presence of small cluster of PAH could be confirmed by cross-polarization experiments at variable contact times (Figure 4c), identifying protonated $\mathrm{sp}^{2}$ sites. In fact, the resonance at $127 \mathrm{ppm}$ can actually be deconvoluted with two peaks, at $125 \mathrm{ppm}$ and $131 \mathrm{ppm}$, identifying, respectively, protonated and non-protonated species, as better described later and shown in Figure 4. The structure of Figure 2g excludes the existence of protonated arene groups. 
Complete disappearance of the furanic-based network only occurs after thermal treatment at $550^{\circ} \mathrm{C}$ (Figure 2c), where only the polyaromatic scaffold remains. The 151/110 ppm correlation no longer exists but a strong on-diagonal peak at 127 ppm (polyaromatic scaffold) and a less intense correlations between 151/121 ppm is observed instead. These resonances are classically attributed to phenolic carbons (dotted line) close to quaternary and protonated $\mathrm{sp}^{2}$ carbon sites, as shown in Figure $2 \mathrm{~h}$. These important structural changes are also confirmed by the drastic reduction in oxygen content, which is reduced from nearly $30 \mathrm{wt} \%$ to about $13 \mathrm{wt} \%$. At $750^{\circ} \mathrm{C}$, the material is constituted by an extended aromatic scaffold composed of polyaromatic hydrocarbons (Figure 2d) as also suggested by single-pulse experiments in Figure 1 and as expected after a high-temperature treatment. 


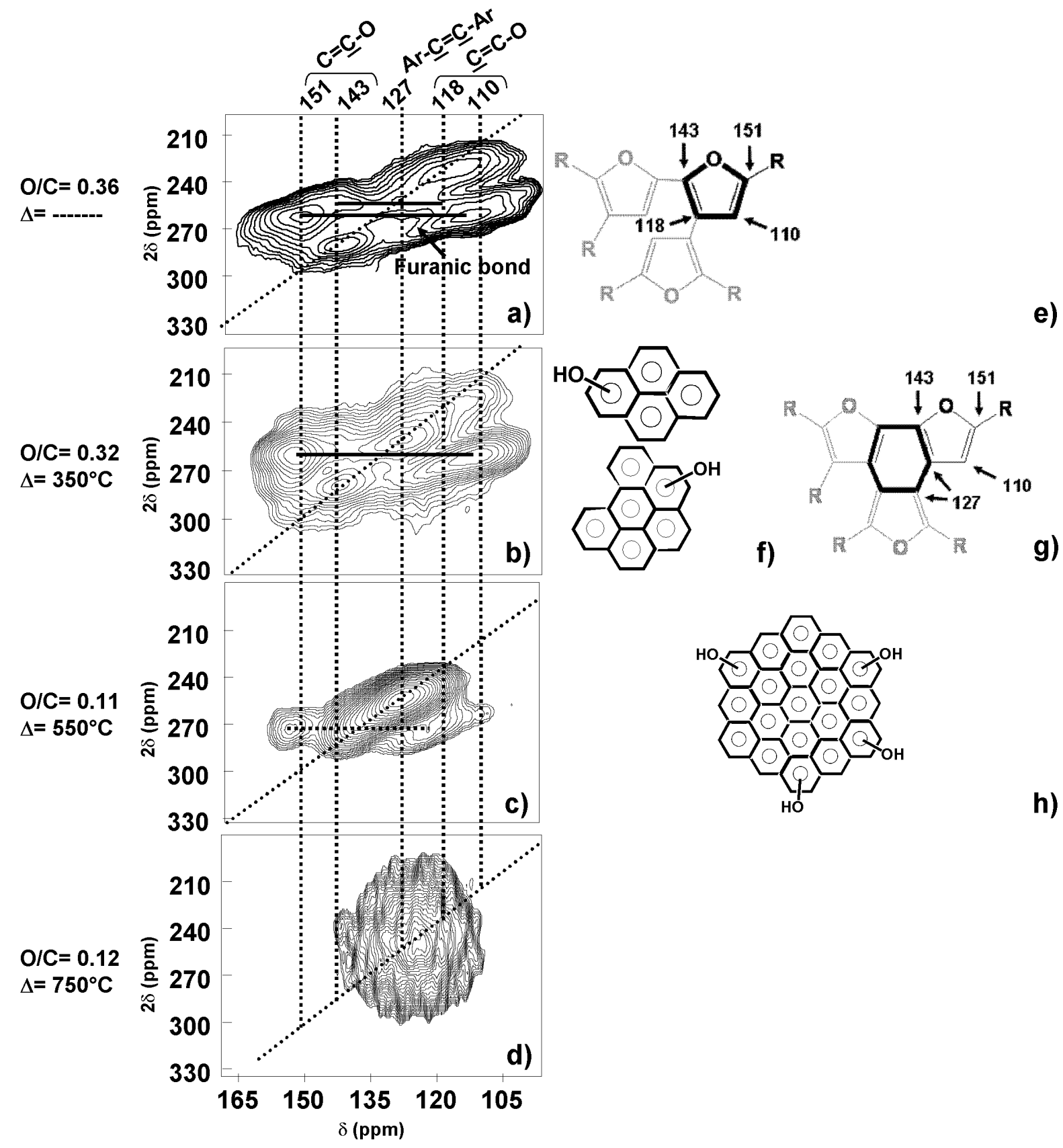

Figure 2 - a-d) Highlight in the 165-100 ppm region of ${ }^{13} \mathrm{C}-{ }^{13} \mathrm{C}$ SQ-DQ experiments (CP-filtered) performed on as-synthesized and calcined hydrothermal carbons. a) $\mathrm{HTC}$-glucose obtained at $\mathrm{T}=180^{\circ} \mathrm{C}$; pyrolized $\mathrm{HTC}$ glucose at (b) $\mathrm{T}=350^{\circ} \mathrm{C}$, (c) $\mathrm{T}=550^{\circ} \mathrm{C}$ and (d) $\mathrm{T}=750^{\circ} \mathrm{C}$. e-g) Peak attribution (values are in ppm) and proposed structures of the basic structural unit derived from SQ-DQ experiments shown in (a) and (b). h) Scheme of the structure derived from SQ-DQ experiments shown in (c). On the left, O/C indicates the oxygen-to-carbon molar ratio while $\Delta$ indicates the calcination temperature.

Comparison with direct calcination process. When glucose is pyrolyzed directly at $350^{\circ} \mathrm{C}$

(sample: glucose $\left(\Delta 350^{\circ} \mathrm{C}\right)$ ) without previous hydrothermal treatment, similar results to HTC- 
glucose $\left(\Delta 350^{\circ} \mathrm{C}\right)$ are obtained from both the compositional (Table 1) and spectroscopic points of view, if one does not take into account the peak of unreacted glucose at $\delta=75 \mathrm{ppm}$ and which undoubtedly contributes to the higher oxygen content (35 wt\% instead of $29 \mathrm{wt} \%$ ). The central region (151-100 ppm) of the ${ }^{13} \mathrm{C}$ CP MAS NMR spectra of HTC-glucose $\left(\Delta 350^{\circ} \mathrm{C}\right)$ (Figure 3b) and glucose $\left(\Delta 350^{\circ} \mathrm{C}\right)$ (Figure 3a) show similar envelopes, except for the resonance at $\delta=110 \mathrm{ppm}$, which seems to be less intense in the second sample.

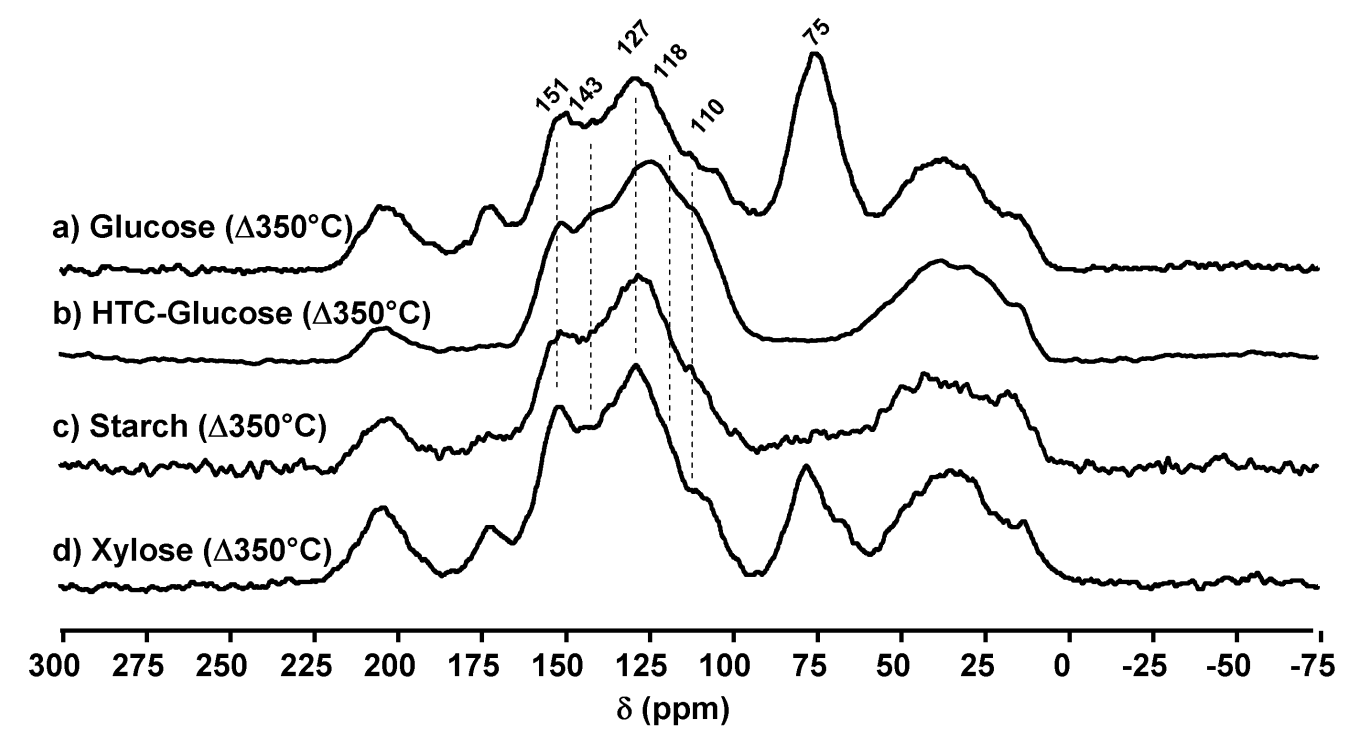

Figure $3-{ }^{13} \mathrm{C}$ CP-MAS NMR spectra on a series of pyrolyzed HTC-glucose and several pure carbohydrates at $\mathrm{T}=350^{\circ} \mathrm{C}$ (rate: $\left.1^{\circ} / \mathrm{min}\right)$.

When starch and xylose undergo pyrolysis at $350^{\circ} \mathrm{C}$, their ${ }^{13} \mathrm{C} \mathrm{CP}$ MAS NMR spectra in Figure 3 c,d are also very similar to the one of glucose $\left(\Delta 350^{\circ} \mathrm{C}\right)$. Several things should be pointed out. 1) The pyrolysis of carbohydrates is a largely studied topic, even if, as recalled in the introduction, recent advances in solid state NMR have allowed more precise insights on the resulting coal structure. ${ }^{13} \mathrm{C}$ NMR spectra obtained here for pyrolyzed starch, xylose and glucose are completely coherent with what has been already published in the literature. ${ }^{13,14,16,17}$ Similar structures are also obtained on calcined cellulose. This is very interesting because, during pyrolysis, the nature of the carbohydrates does not seem to make any difference when it comes to comparing the final structure of the char at $\mathrm{T}>300^{\circ} \mathrm{C}$, even if it is well-known that reducing sugars, like glucose, do not show the 
same degradation chemistry as compared to non-reducing sugars, like starch and cellulose. ${ }^{48}$ 2) It is well-known that pyrolysis of glucose produces large amounts of volatile furanic groups and a nice overview and comparative study on this topic is reported in reference 48. Then, one would expect to find furanic-rich coals but, even if the existence of furans is supposed and accepted by some authors, ${ }^{15,16}$ furanyl structures were never really discussed in detail and their presence was not clearly demonstrated. We attempted ourselves (results not shown) to isolate a furan-rich structure in calcined $\left(\mathrm{T}=350^{\circ} \mathrm{C}\right.$; two different heating rates were tested, $1^{\circ} \mathrm{C} / \mathrm{min}$ and $\left.6^{\circ} \mathrm{C} / \mathrm{min}\right)$ glucose-derived carbons (no hydrothermal process involved). Unfortunately, for residence times below 4 hours, the glucose signal is still very intense and nothing can be told about the inner structure of the char. At longer residence times, the resonance corresponding to PAH is already detected. This approach was then, unfortunately, inconclusive with respect to the presence of furans.

When it comes to the structural study of HTC and according to data collected so far, the coalification process seems to be different, or, at least its chemistry seems to be richer. For instance, the structure of HTC obtained from $x \operatorname{lose}^{7 \mathrm{a}}$ is closer to its calcined form (Figure 3d) than to a furan-rich type of material. We have previously attributed this difference to the pentose nature of xylose and to the fact that its main dehydration product is furfural instead of hydroxymethyl furfural. The presence of co-reactants, as we have shown for nitrogen-containing compounds like proteins and aminoacids, ${ }^{23,24,28}$ can definitely influence the aromatic extent of the carbonaceous scaffold. Nevertheless, in this case, nitrogen can be introduced within the aromatic network in the form of pyrazine or pyridine units, making the material much harder to study and understand ${ }^{28}$. The most interesting results in HTC probably come from comparing starch and cellulose, two nonreducing sugars of high molecular mass. Due to its lower degradation temperature, starch provides furan-rich $\mathrm{HTC}$ at $180^{\circ} \mathrm{C}$ after $12 \mathrm{~h}$ of reaction, just like glucose ${ }^{7 \mathrm{a}}$ while cellulose does not, as largely discussed in reference 49. Finally, reaction temperatures and time during the HTC process do play an important role, as one would expect but results can be, in some cases, puzzling. For instance, if the structure of glucose-derived HTC evolves from furan-rich to arene-rich as a function 
of residence times at $\mathrm{T} \geq 200^{\circ} \mathrm{C}$, cellulose-derived $\mathrm{HTC}$ does not provide any furan-rich structure at all. These aspects are largely discussed in ref. 49.

In the next section, we propose a semi-quantitative evaluation of the furan-to-arene ratio and we will evaluate, using DFT calculation, the possibility that two selected structural models, shown in Figure 2e and Figure 2g, are actually energetically stable, within the framework of hypothesis 1 through 3 discussed above. Conclusions will apply both to HTC and calcination-derived chars.

Quantification of the furan-to-arene units. The presence of large amounts of arene units condensed into polyaromatic structures is of paramount importance from the point view of the application of carbon-based materials. The possibility of making graphene, graphite, nanotubes, etc.. using a sustainable approach is very interesting. Both HTC and calcination at temperatures below $400^{\circ} \mathrm{C}$ provide, according to the processing conditions of the carbohydrate source and according to the source itself, a wide range of carbonaceous materials whose furan-to-arene content is far from being constant. Hereafter, we propose a rapid way of determining such a ratio in a semiquantitative way.

The number of ${ }^{13} \mathrm{C}$ NMR experiments performed both on glucose and other types of carbohydrates have shown that the experimental conditions play a crucial role on the furan-to-arene content making the HTC process relatively different from calcination. Simulation of single-pulse quantitative ${ }^{13} \mathrm{C}$ MAS NMR spectra are able to provide interesting data on the relative amount of furan-to-arene species. Unfortunately, not all samples are best suited for single-pulse experiments due to the long relaxation times and low isotopic abundance of ${ }^{13} \mathrm{C}$. For this reason, we compare two sets of experiments on selected fully ${ }^{13} \mathrm{C}$-enriched HTC samples: single-pulse experiments, which are more reliable and quantitative, and CP-based experiments. Before continuing, it is necessary to define the side conditions of our semi-quantitative study:

- Paramagnetic centers. The presence of paramagnetic centers in carbons and their influence on overall carbon detection has always been a matter of debate. Many studies have been dedicated to 
this topic but a clear answer on the amount of carbon that is actually detected was not provided. In particular, according to the carbon source and pyrolysis conditions (temperature, time) one can detect as low as $26 \%$ of all carbons atoms even if, in general, it was demonstrated several times that all carbon sites can actually be detected in single-pulse experiments. The amount of electron spins increases with temperature and, in particular, sharp increase occurs at $\mathrm{T}>350-400^{\circ} \mathrm{C}$. More details can be found, for instance, in ref. $20,50,51,52$, 53. We have found, without exploring this topic in more details, that HTC-glucose has a clear response in ESR experiments (results not shown), demonstrating the presence of paramagnetic centers, which could, potentially, affect the overall detection of carbon in NMR experiments. This phenomenon is undoubtedly more pronounced at high calcination temperatures. Due to the lack of experimental data we cannot include paramagnetic centers in our model structures at present time but, in principle, this could be done.

- Fitting. We have adapted our procedure from our previous work; ${ }^{\text {7b }}$ in particular, the same peaks employed in the simulation of of HTC-glucose were used, the peak height alone was allowed to vary and a Gaussian lineshape was chosen, as outlined in the experimental section. In order to provide an idea of the error due to the choice of fitting parameters, please consider peak-(c), peak(d) and peak-(f), whose attribution is given in the next paragraph. In Table 1-Sup Mat we provide the fitting details for these peaks and one should keep in mind that Test $\mathrm{N}^{\circ} 1$ has been used throughout our former and this new study. Modification of either the linewidth (Test $\mathrm{N}^{\circ} 2$ ) or Gaussian/Lorentzian ratio (Test $\mathrm{N}^{\circ} 3$ ) or both parameters (Test $\mathrm{N}^{\circ} 4$ ) has a relatively limited impact on the $[(\mathrm{c})+(\mathrm{d})] /(\mathrm{f})$ ratio, the highest discrepancy being a value $40 \%$ higher in Test $\mathrm{N}^{\circ} 2$. The same peaks and simulation parameters are also used to simulate CP spectra. No impact at all of the fitting procedure was found on the cross-polarization experiments at variable contact time (Figure 4).

- Cross-polarization. CP experiments are notoriously not quantitative, unless a good knowledge of the spin dynamics is provided. Nevertheless, under the appropriate conditions, CP can be employed for semi-quantitative purposes. In particular, if the amount of protons is uniform throughout the sample and the different chemical groups exhibit a similar relaxation behavior under 
spin-lock (T1rho), then, for one or more optimum contact time values, the CP spectrum can be comparable with the single-pulse experiment and then considered as being quantitative. In this work, these criteria are satisfied: 1 ) elemental analysis (Table 1) shows that all samples treated at $350^{\circ} \mathrm{C}$ have a similar content of protons $\left(\mathrm{H}_{\text {average }}=4.51 \pm 0.33 \mathrm{w} \%\right)$ among them and with respect to the reference compound, HTC-glucose; 2) CP behavior of HTC-glucose and HTC-glucose $\left(\Delta 350^{\circ} \mathrm{C}\right)$ is similar in the aromatic region; in particular, the evolution of the integrated area as a function of contact time was presented in Ref. $7 \mathrm{~b}$ for HTC-glucose and in Figure $4 \mathrm{c}$ for HTC-glucose $\left(\Delta 350^{\circ} \mathrm{C}\right)$ : peak-(d) and peak-(f) have a typical behaviour of protonated carbons while all other display an evolution with contact time $\left(\mathrm{t}_{\mathrm{CP}}\right)$ typical for non-protonated carbons. Despite these differences in the protonation extent, relaxation under spin-lock at contact times higher than $1000 \mu$ s shows that all chemical groups have a relatively homogenous behavior. For this reason, a contact time between 1 and $3 \mathrm{~ms}$ is a good compromise between gain in sensitivity and homogeneous excitation, minimizing ${ }^{1} \mathrm{H}$ relaxation effects in the rotating frame during $\mathrm{CP}^{7 \mathrm{~b}}$. 

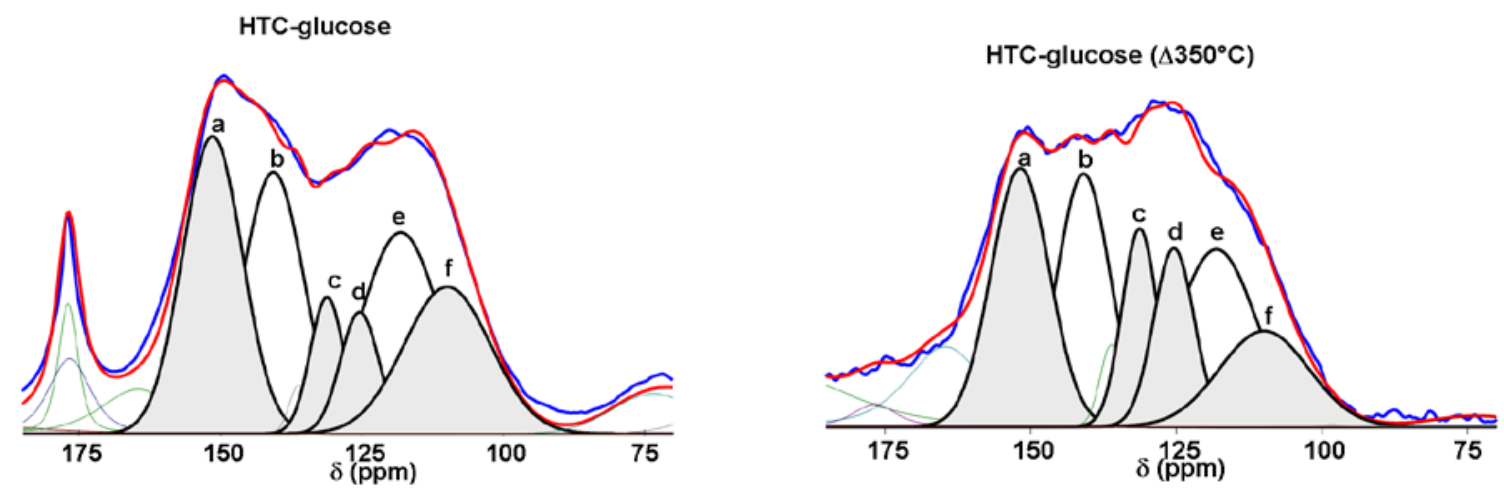

a)

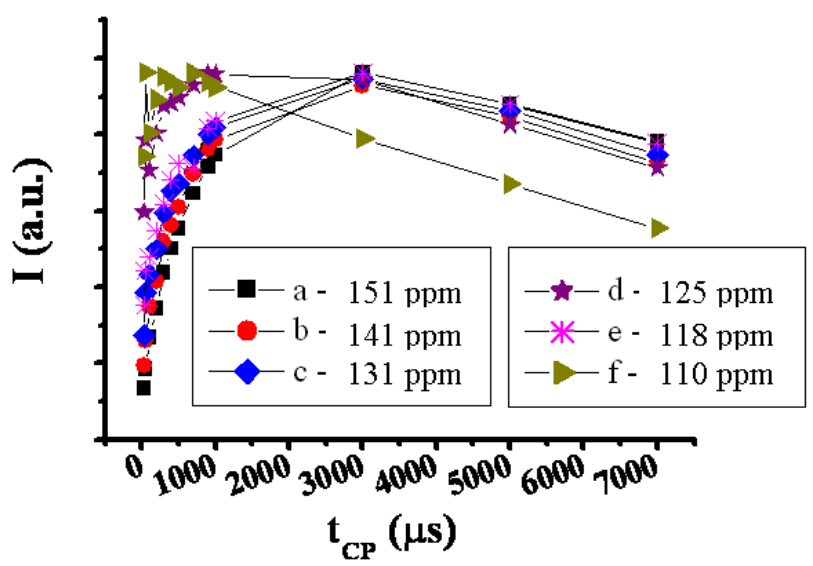

c)

Figure 4 - Simulated single-pulse ${ }^{13} \mathrm{C}$ MAS NMR experiments performed on a) HTC-glucose and b) HTC-glucose $\left(\Delta 350^{\circ} \mathrm{C}\right)$. Blue envelope corresponds to experimental data while red one refers to simulation. For attribution, please refer to Figure $2 \mathrm{e}$ and g where: peak-(a)= $151 \mathrm{ppm}$; peak-(b)=143 ppm; peak-(e)=118 ppm; peak-(f)= $110 \mathrm{ppm}$. Peak-(c) and peak-(d) resonate, respectively, at $131 \mathrm{ppm}$ and $125 \mathrm{ppm}$ and account for the aromatic resonances. The area calculated from grey-shaded peaks (c), (d) and (f) are used in Eq.1. Shaded peak-(a) corresponds to both furanic and arene peaks. Gaussian lineshape was used for all peaks between the 170-90 ppm. c) Evolution of the normalized integrated intensity of cross-polarization experiments as a function of contact time ( $\left.t_{\mathrm{CP}}\right)$ performed on the HTC-glucose $\left(\Delta 350^{\circ} \mathrm{C}\right)$ sample; the notation a through $\mathrm{f}$ corresponds to the peaks discussed above.

Attribution of peaks (a) to (f) is based on Figure 2(e,g) but one should keep in mind the following: 1) peak-(a) at 151 ppm can correspond to substituted $\alpha$-carbon of a furan unit or an etherified phenolic group. Hence, the attribution of this resonance cannot be completely unambiguous; 2) The signal at $110 \mathrm{ppm}$ is assumed here to be related to one single furan unit as its strongest correlation only occurs with the cross-peak at $151 \mathrm{ppm}$. Even if resonances at this chemical shift have been reported in lignin-type networks, ${ }^{45}$ we believe this assumption to be 
reasonable. The very strong $151-110$ cross-peaks in HTC-glucose and HTC-glucose $\left(\Delta 350^{\circ} \mathrm{C}\right)$ do not seem to be much affected neither in intensity nor in shape by the temperature treatment. Additionally, the prominent a $151-121$ ppm cross-peak in the HTC-glucose $\left(\Delta 550^{\circ} \mathrm{C}\right)$ sample of Figure 2c, clearly attributed to a OH-substituted arene group, suggests that they are most likely to be expected at higher chemical shifts than $110 \mathrm{ppm}$, as observed in lignins. 3) The main resonance at 127 ppm observed in the SQ-DQ experiments in Figure 2 and attributed to condensed arene groups results from the combination of two peaks, peak-(c) at $131.2 \mathrm{ppm}$ and peak-(d) at $125 \mathrm{ppm}$. CP MAS experiments presented before ${ }^{7 b}$ allowed to separate the contribution of both peaks. Here, we decided to keep them separated but in the following discussion their overall sum is considered. The discussion hereafter is based on these important assumptions which confer to this a semiquantitative statue.

After integrating the intensities of these peaks (Figure 4), it is possible to calculate the aromatization extent. I(c) and I(d), corresponding, respectively, to the integrated area of peak-(c) and peak-(d), should provide the extent of aromatization with respect to furanic content, outlined I(f) and corresponding to peak-(f). It is important to note that I(f) only accounts for 1 single carbon (and identifying one single furan unity) while the sum of $[\mathrm{I}(\mathrm{c})+\mathrm{I}(\mathrm{d})]$ accounts for a number of carbons varying between 4 and 6, according to the amount of oxygen substitution in the arene unit. The furan-to-arene ratio is then obtained by the following equation,

$$
\frac{I(f)^{*} n}{[I(c)+I(d)]}
$$

The value $n$ relates to the number of non-oxygenated arene carbons and it can be estimated by comparing the integrated intensities, $[\mathrm{I}(\mathrm{c})+\mathrm{I}(\mathrm{d})]$, of all non-oxygenated $\mathrm{sp}^{2}$ carbons resonating at $127 \mathrm{ppm}$, to the integrated intensity, I(a), of the oxygenated $\mathrm{sp}^{2}$ carbons at $150 \mathrm{ppm}$ from which the contribution of furans, I(f), is subtracted. For the HTC-glucose and HTC-glucose $\left(\Delta 350^{\circ} \mathrm{C}\right)$ samples, the amount of oxygenated $\mathrm{sp}^{2}$ carbons gives an average value of between 1 and 2 . In this case, $n$ 
ranges between 4 and 5, which means that between one and two carbons per six-membered arene rings.

Reference

experiments

$$
\text { 1= HTC-glucose }
$$

2 $=$ HTC-glucose $(\Delta 350)$
(A)

HTC-glucose $\mathrm{t}=24 \mathrm{~h}$
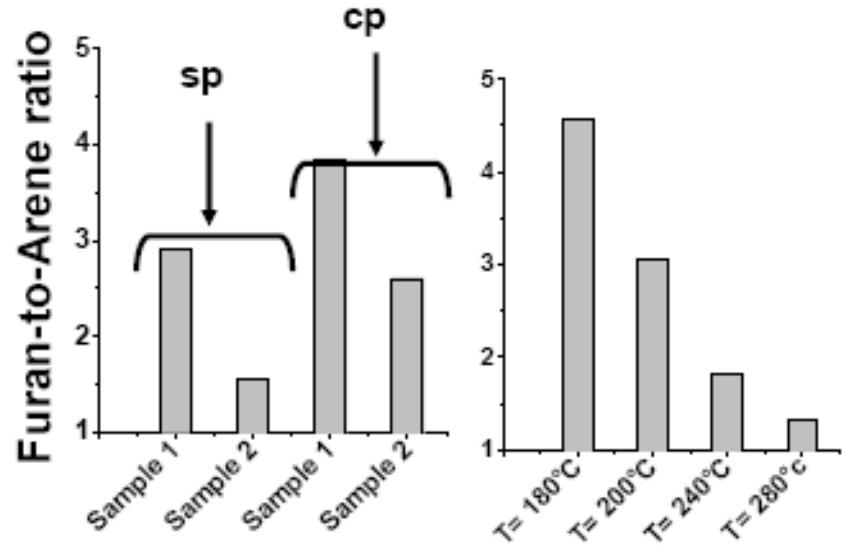

(B)

HTC-glucose

$\mathrm{T}=240^{\circ} \mathrm{C}$
(C)

Calcined

$\mathrm{T}=350^{\circ} \mathrm{C}$

Figure 5 - Furan-to-arene ratio for a series of hydrothermal (A-B) and calcined (C) carbons. Values were calculated according to Eq.1, with $n=4.5$. For spectroscopic data for HTC-glucose samples treated at different residence times (A) and temperatures (B), one can refer to Ref. 49. Spectroscopic data for (C) are given in Figure 3. sp and $c p$ stand for, respectively, single-pulse and cross-polarization NMR experiments.

Under these conditions, we exploited Eq.1 to account for the intensities of peak-(a) through peak(f) in CP MAS experiments. Figure 5 shows the evolution of the amount of furanic versus arene species with $n=4.5$. First of all, the comparison between single-pulse and CP experiments at $\mathrm{t}_{\mathrm{c}}=3$ ms (Figure 5, Reference experiment section) both performed on a furan-rich (HTC-glucose) and a furan-poor (HTC-glucose $\left(\Delta 350^{\circ} \mathrm{C}\right)$ ) sample shows that $\mathrm{CP}$ experiments systematically overestimate the amount of furan unit by about $1.0 \pm 10 \%$ unit in both samples. The rest of the data in Figure 5 were not rescaled on the basis of this systematic error but one should keep it in mind when working with CP-based data. The (A) and (B)-sections in Figure 5 show, respectively, some results obtained on hydrothermally-derived HTC-glucose treated at $\mathrm{T}=240^{\circ} \mathrm{C}$ between $2<\mathrm{t}<72 \mathrm{~h}$ and between $180^{\circ} \mathrm{C}<\mathrm{T}<280^{\circ} \mathrm{C}$ at $\mathrm{t}=24 \mathrm{~h}$ and spectroscopic data are shown in ref. 49 . In both cases, the effect of increasing temperature or increasing residence time under hydrothermal conditions results into a 
clear increase of the polyaromatic extent into the final material. Without being too precise, one can safely say that the number of furan groups with respect to arene groups varies between $4.5 \pm 1$ and 1 \pm 1 . The effect of residence time on the presence of polyaromatic network is striking in (B)-section. For comparison purposes, one can observe in (C)-section of Figure 5 the furan-to-arene ratio of several pyrolyzed carbohydrates (spectra are given in Figure 3 b-d). CP experiments indicate the same trend and, in particular, charred carbohydrates have a close 1:1 furan-to-arene ratio. Interestingly, the results are comparable with the HTC materials obtained between $240^{\circ} \mathrm{C}<\mathrm{T}<$ $280^{\circ} \mathrm{C}$.

Process-to-structure relationship. Scheme 2 makes a summary of the different reaction pathways which were described above. The final structure is amorphous on the large scale but one can assume the existence of local repeating units.

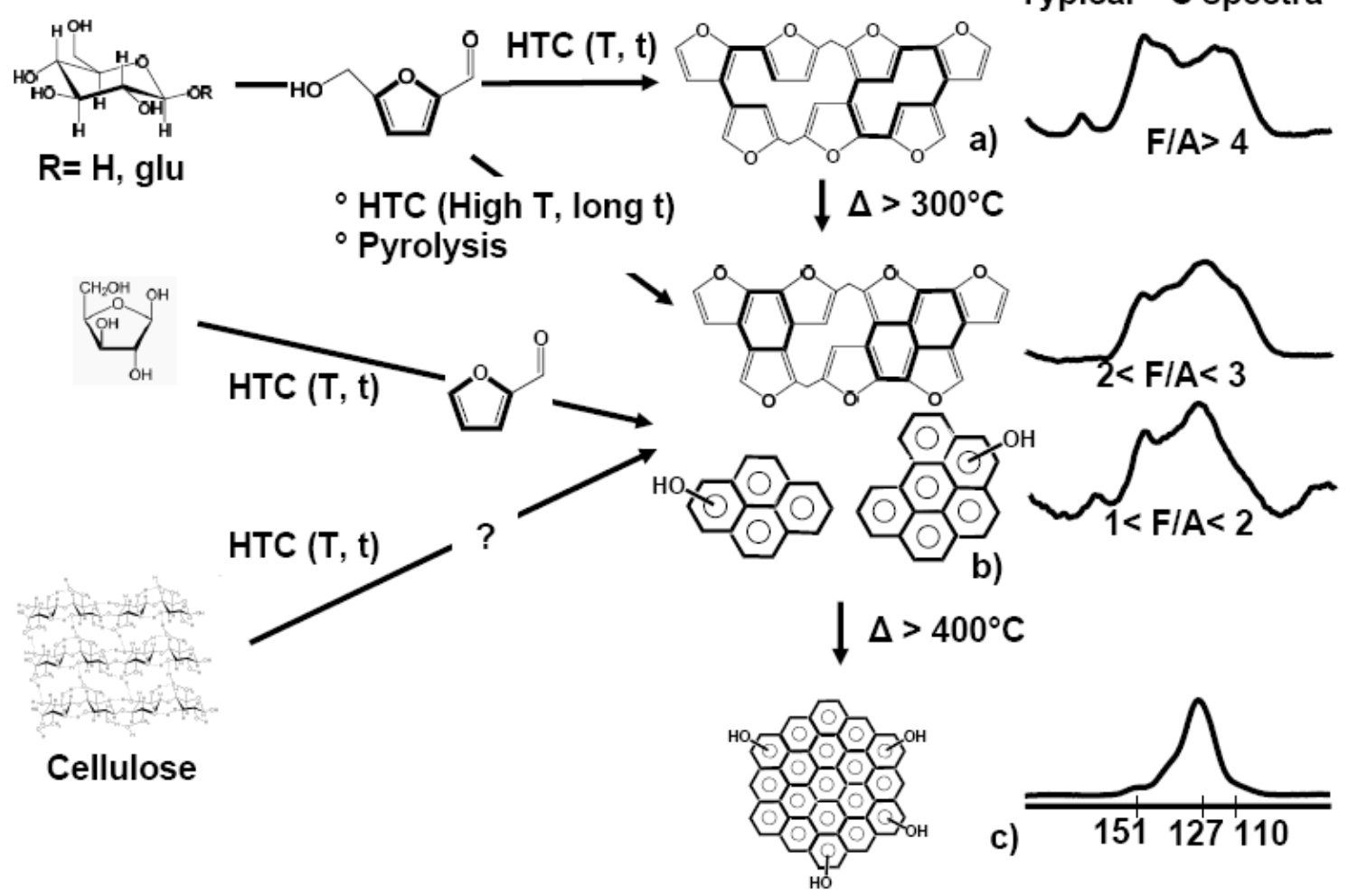

Scheme 2 - Relationship between HTC and calcination processing conditions of carbohydrates, including cellulose, ${ }^{49}$ and detected structures. On the right side, indicative solid state ${ }^{13} \mathrm{C}$ NMR spectra are provided as a function of the ratio furanic $(F)$ to arene $(A)$ groups. 
- Structure-(a) is a furan-rich structure which is only observed in the case of hydrothermallytreated carbohydrates, and which respects at best the relative peak intensities of the single pulse NMR spectra and the connectivity path identified by the SQ-DQ experiments. This structure is temperature, time and source-dependent. In fact, it can only be observed either at low residence times or at low HTC temperatures (below $200^{\circ} \mathrm{C}$ ). Interestingly, at $\mathrm{T}=180^{\circ} \mathrm{C}$, this is the only structure observed even at $72 \mathrm{~h}$ residence time (Ref. 49). Use of pentoses under mild conditions or use of cellulose (Ref. 49) did not provide a furan-rich structure at all. Additionally, this structure cannot be identified in calcined products.

- $\quad$ Structure-(b), which is very common in both HTC and calcination and obtained under various conditions, was specifically discussed above. It main feature consists in containing higher amounts of arene groups coming either from condensed three-membered furanic units or from PAH clusters. A coexistence between PAH and structure-(a) cannot be excluded, as hypothesized above. According to the furan-to-arene ratio, slightly different NMR spectra can be obtained (sample spectra are given next to the structure). The typical ${ }^{13} \mathrm{C}$ NMR spectrum shows a peak at 110 ppm whose intensity depends on the amount of furanic units relative to arene ones. When the number of furanic units approximately equals the arene ones (see Figure 5), its intensity is lower than the peak at $151 \mathrm{ppm}$ and they will appear asymmetric. The asymmetric behavior is related to the presence of phenolic carbon atoms, as discussed above. On the contrary, when the number of furanic units is roughly between 2 and 3 times higher than the arene ones, the spectrum is still characterized by a dominant peak at 127 ppm but two more symmetric resonances will appear at 110 and 151 ppm. High hydrothermal temperatures $\left(>200^{\circ} \mathrm{C}\right)$ and long residence times $(>24 \mathrm{~h})$ generally favor structure-(b) for simple and noncrystalline hexose-based carbohydrates. Pentoses, like xylose, also favor structure-(b) under mild hydrothermal treatment conditions, most likely due to the presence of furfural. Interestingly, hydrothermal treatment of cellulose always provides structure-(b) under any temperature conditions explored. The reason for this is discussed more deeply in ref. 49. This 
particular structure is generally observed after pyrolysis, as shown in Figure 3 and in other known systems. ${ }^{11,16}$ These considerations indicate that the main difference between calcination and HTC processes concerns the relative amount of furans with respect to arene units. Since these compounds cannot be isolated in calcined systems, an important difference in their reactivity under nitrogen with respect to water under pressure must explain the differences in the final structures. One should not forget the presence and influence of paramagnetic centers, which may mask part of the carbon atoms and influence the overall furan-to-arene ratio. This aspect was not considered in this work.

- Finally, calcination at higher temperatures increases the number of arene units and reduces the amount of both furanic and phenolic groups (Scheme 2c). This behavior, well-known for pyrolysis of carbohydrates is verified also for HTC-based materials.
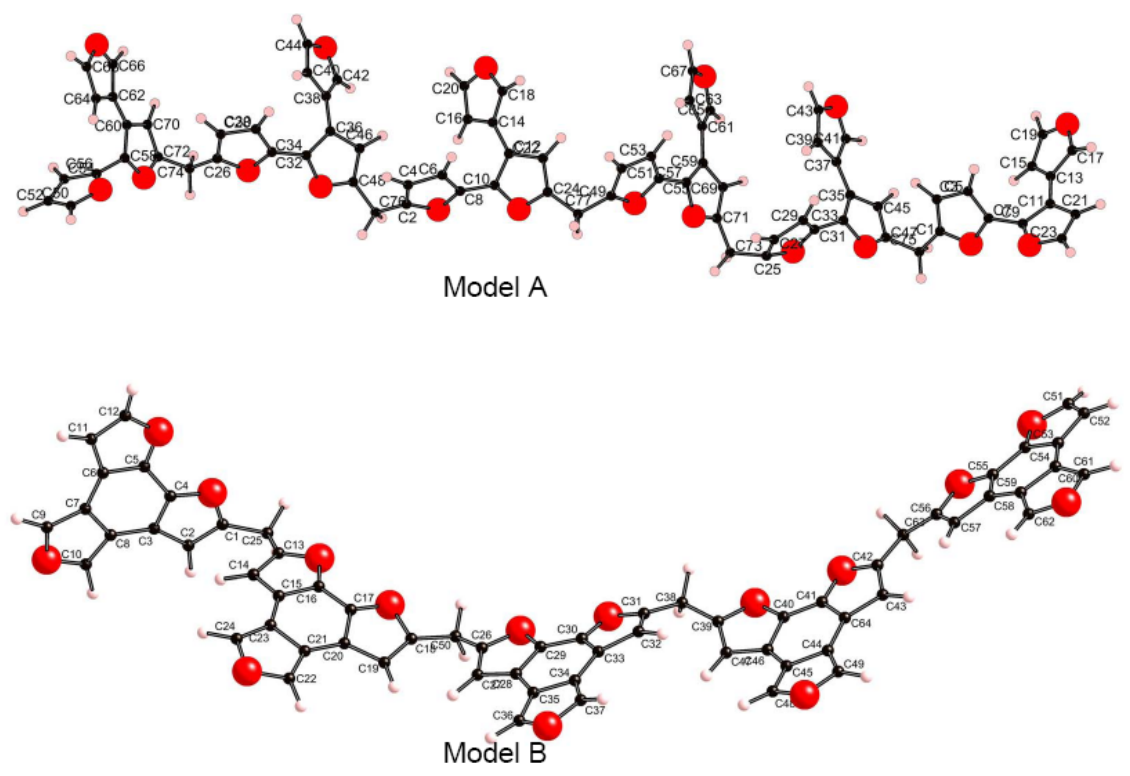

Figure 6 - Modeled structures were obtained through DFT geometry optimisation based on the structural units proposed in Figure 2e,g and Scheme 2

To better interpret NMR data, two modeled structures were obtained and validated through DFT geometry optimisation based on the single units proposed in Figure 2 e and g and Scheme 1. Structure A in Figure 6 was obtained through polymerization of furan rings connected via $\alpha-\alpha, \beta-\beta$ and $\alpha-\mathrm{CH}_{2}-\alpha$ bonds while the hypothetical structure B in Figure 6 is based on 3 furan rings around 
an arene core, connected through $\alpha-\mathrm{CH}_{2}-\alpha$ bonds between furanic units. Corresponding NMR parameters were also calculated (Table 2 Sup Mat) to be compared to experimental ones. Figure 7 shows the main units for schemes $2 \mathrm{a}$ and $2 \mathrm{~b}$ and the average chemical shift values for the four types or carbon environments in each structure. Experimental chemical shift are reported as straight solid lines while calculated ones are reported as bars. Errors derive from averaging the calculated chemical shifts of models A and B.

\section{Model A}

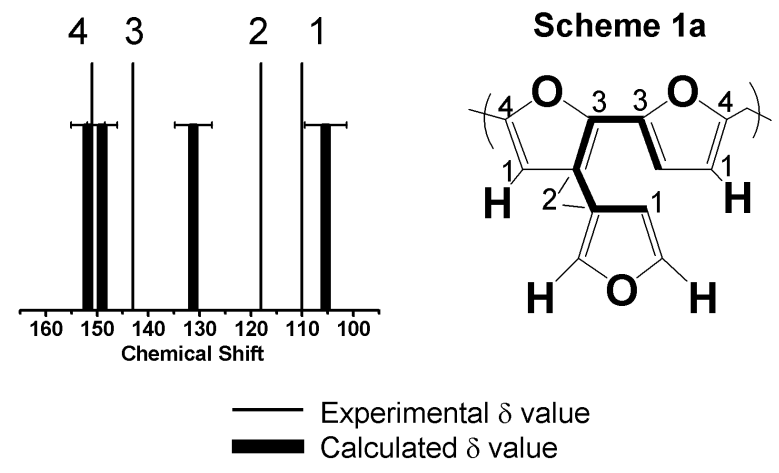

\section{Model B}

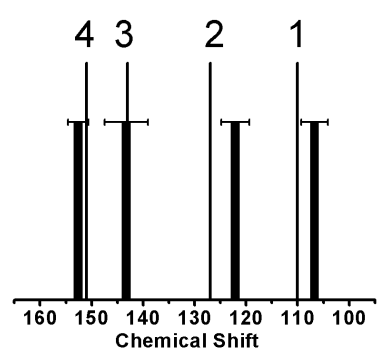

Scheme 1b

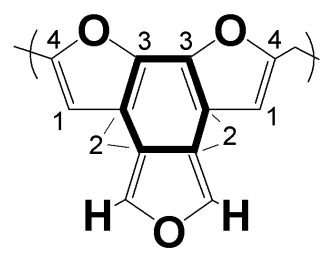

Figure 7 - Average chemical shifts (and standard deviation) calculated for model structures A and B. Thin lines indicate the experimental chemical shift values of the corresponding sample. Full list of calculated chemical shift is given in Table 2 Sup Mat.

- Positions 1 and 4 are well described by either model A or model B and calculated chemical shifts are comparable with experimental ones within error.

- Most important, the calculated chemical shift values for position 3, directly bonded furan rings via alpha carbon, are also consistent with experiment. In particular, the calculated 
chemical shift for this specific position is always (both in model A and B) slightly more shielded with respect to position 4, as observed in all NMR experiments.

- Calculated values for position 2 are less consistent with experimental values and the biggest discrepancy (about 13 ppm) occurs for the as-synthesized HTC sample. After calcination, the calculated $\left(\delta_{\text {average }}=122 \pm 3 \mathrm{ppm}\right)$ and experimental $\left(\delta_{\exp }=127 \mathrm{ppm}\right)$ values are closer. Nevertheless, condensation between two furan rings into a 6-member ring via their beta carbons (positions $1 \rightarrow 2$ ) results in a shift towards a more unshielded values, as observed for both experiment and simulation.

Finally, NMR calculations show that after calcinations, the overall chemical shift value of carbon species corresponding to position 2 increases (of $\approx 8$ ppm from model A to B) while the one related to position 1 decreases slightly; meanwhile, positions 3 and 4 show similar values in both models. The ${ }^{13} \mathrm{C}$ NMR spectral evolutions with temperature show exactly the same trend (Scheme 2). Interestingly, the hypothetical structure B (refer to discussion above) has a very good match between the experimental and calculated chemical shift values, which straightens the hypothesis number 2 formulated in the previous section.

It would be of course very interesting to know the exact mechanism of formation of HTC materials. Unfortunately, even if an abundant literature exists in the domain of furan polycondensation, very little is known so far mainly because of the complexity of the reaction medium during hydrothermal treatment and the reactivity of the furan moiety. The comparison between structures (a) and (b) in Scheme 2 suggests that (b), the richest in arene groups, can be obtained either via a calcination step, which induces inter-furan condensation reactions, or via a direct homo-condensation of furfural. The condensation reaction may occur in the polyfuran resin to form 6-members rings, as supported by quantitative single pulse NMR and by structural modeling and chemical shift calculation discussed above. 
Which is the possibility of creating such bonds in furan chemistry? $\alpha-\alpha$ bond was reported ${ }^{54}$ preferentially in presence of a non-substituted $\alpha$-site, which is the case of furfural (Scheme 2b) or simply furan. On the contrary, HMF may undergo easier polymerization where furan units are spaced with a $\mathrm{CH}_{2}$ or a $=\mathrm{CH}$ - group, as it happens for furfuryl alcohol under acidic catalysis. ${ }^{55}$ Nevertheless, considering the amount of $\alpha-\alpha$ bonds even in the case of HMF-derived carbons, a non-speculative reaction mechanism lacks at the moment. The major degradation products of HMF are $1,2,4$ benzenetriol $^{56}$ and levulinic acid under subcritical conditions while furfural is rather formed under supercritical conditions. ${ }^{57}$ Furfuryl alcohol (a decarbonylation product of HMF) and furfural can also be formed (though in minor quantity) and they can actually be the possible reaction intermediates leading to the $\alpha-\alpha$ bond and to the condensation on the alcohol side. These mechanisms should most likely be driven by acid catalysis (formic acid is found in the final medium $^{\text {tb }}$ ). $\beta-\beta$ cross-linking between furanic chains eventually takes place even if the Diels-Alder reactions, reported for these systems ${ }^{54}$ and involving $\alpha$-carbons instead, seem to be less concerned with respect to simple condensation.

\section{Conclusions}

The increasing exploitation of the hydrothermal treatment of biomass for material science application requires a clear picture of the structure of the final carbonaceous materials. So far, several models have been proposed to interpret a large amount of structural data obtained from FTIR, XPS, elemental analysis and NMR; nevertheless, some incoherences still exist and it is still not clear whether to consider hydrothermal carbons closer to furan-based polymers or char. Basing our study on solid state ${ }^{13} \mathrm{C}$ NMR, we were able to study and compare a large number of both hydrothermally-treated and calcined samples and establish a relationship between processing conditions and material structure. In particular, the amount of condensed arene groups, identifying poly-aromatic hydrocarbon clusters, can be estimated with respect to furans. 
Semi-quantitative cross polarization experiments on a number of glucose-derived HTC (both here and in reference 49) performed under “classical” conditions $\left(\mathrm{T}=180^{\circ} \mathrm{C}\right.$ at $\left.\mathrm{t}<72 \mathrm{~h}\right)$ give a good approximation of the furan-to-arene ratio, estimated to 4.5 . Calcination at $350^{\circ} \mathrm{C}$ of both the $\mathrm{HTC}$ or the raw carbohydrate, on the contrary, provide arene-rich chars, where the furan-to-arene ratio falls below 1. Interestingly, arene-rich structures can also be obtained either under stronger HTC conditions $\left(\mathrm{T}>200^{\circ} \mathrm{C}\right)$ or when using different biomass sources like cellulose. On the contrary, calcination alone does not provide furan-rich structures, making this process less rich, or less controllable, in terms of carbon chemistry.

Combining these observations with more advanced ${ }^{13} \mathrm{C}-{ }^{13} \mathrm{C}$ Single-Quantum Double-Quantum experiments performed on model materials, we make several hypotheses about the nature of the possible carbonaceous structures obtained after HTC and calcination, both rich in interconnected furan rings and possible candidates as intermediates for the formation of PAH. DFT calculations and a comparison between experimental and calculated ${ }^{13} \mathrm{C}$ chemical shift values shows an overall agreement between the models and real structures. We think that these data will contribute to a better description of the different stages and structural changes that occur to carbohydrates under both hydrothermal and calcination treatment and before final graphitization at higher temperature.

Finally, three different reaction pathways leading from carbohydrates to various carbonaceous materials with a different furan-to-arene ratio have been proposed. For the first time, we put in relationship processing conditions (HTC, calcination, temperature, residence time) and carbohydrate source with the carbon structure. An important distinction has to be made between monosaccharides, polysaccharides and cellulose. In fact, we show that cellulose (one should refer to Ref. 49 for more experimental details), being a more thermally-stable compound than glucose and starch, never exhibits a furan-rich character, even under similar HTC conditions. The behaviour of cellulose is very close to the one of xylose, for instance. For most carbohydrates, on the contrary, it exists the possibility to tune their PAH content after the HTC process. 


\section{Acknowledgements}

DFT calculations were performed on the IDRIS supercomputer centre of the CNRS (Project 091461). The Direction des Relations Internationales (DRI) office of Université Pierre et Marie Curie (UPMC, Paris, France) is kindly acknowledged for its financial support (03/06/2010 session). Max Planck Society is kindly acknowledged for the financial support. We kindly acknowledge reviewers $\mathrm{N}^{\circ} 4$ and $\mathrm{N}^{\circ} 6$ for their precious and sound work which highly contributed to the final quality of this manuscript.

\section{References}

${ }^{1}$ a) B. Hu, S.-H. Yu, K. Wang, .L Liu, X.-W. Xu, Dalton Trans., 2008, 5414-5423; b) M.-M. Titirici, M. Antonietti, Chem. Soc. Rev., 2010, 39, 103-116); c) B. Hu, K. Wang, L. Wu, S.-H. Yu,, M. Antonietti, M.-M. Titirici Adv. Mater. 2010, 22, 813-828; d) A. Funke, F. Ziegler, Biofuel Bioprod. Bior., 2010, 4, 160-177

2 a) R. J. White, V. L. Budarin, J. H. Clark ChemSusChem. 2008, 1, 408-411.; b) C. Yao, Y. Shin, L. Q. Wang, C. F. Windisch, W. D. Samuels, B. W. Arey, C. Wang, W. M. Risen, G. J. Exarhos J. Phys. Chem. C. 2007, 111, 1514115145. c) V. L. Budarin, J. H. Clark, R. Luque, D. J. Macquarrie, A. Koutinas, C. Webb Green Chem. 2007, 9, $992-995$. d) V. Budarin, R. Luque, D. J. Macquarrie, J. H. Clark Chem.-Eur. J. 2007, 13, 6914-6919. e) S. H. Yu, X. J. Cui, L. L. Li, K. Li, B. Yu, M. Antonietti, H. Colfen Adv. Mater. 2004, 16, 1636 f) M. M. Tusi, M. Brandalise, O. V. Correa, A. Oliveira Neto, M. Linardi, E. V. Spinacé. 2007, 10, 171-175. g) M. Sevilla, G. Lota, A. B. Fuertes J. Power Sources. 2007, 171, 546-551. h) H. S. Qian, G. F. Lin, Y. X. Zhang, P. Gunawan, R. Xu Nanotechnology. 2007, 18. i) X. J. Cui, M. Antonietti, S. H. Yu Small. 2006, 2, 756-759. l) X. M. Sun, J. F. Liu, Y. D. Li Chem.-Eur. J. 2006, 12, $2039-2047$. m) X. M. Sun, Y. D. Li Angew. Chem.Int. Edit. 2004, 43, 597-601. n) H. X. Yang, J. F. Qian, Z. X. Chen, X. P. Ai, Y. L. Cao J. Phys. Chem. C. 2007, 111, 14067-14071. o) K. Zhu, K. Egeblad, C. H. Christensen Eur. J. Inorg. Chem. 2007, 3955-3960. p) J. Hu, H. Li, X. J. Huang Solid State Ion. 2007, 178, 265-271. q) M.-M. Titirici, M. Antonietti, A. Thomas Chem. Mat. 2006, 18, 3808-3812. r) X. Sun, Y. Li Angew. Chem., Int. Ed. 2004, 116, 3915-3919

${ }^{3}$ M.-M. Titirici, A. Thomas, S.-H. Yu, J.-O. Muller, M. Antonietti, Chem. Mater. 2007, 19, 4205

${ }^{4}$ M.-M. Titirici, A. Thomas, M. Antonietti, J. Mater. Chem. 2007, 17, 3412

${ }^{5}$ V. Budarin, J. H. Clark, J. J. E. Hardy, R. Luque, K. Milkowski, S. J. Tavener, A. J. Wilson, Angew. Chem. Int. Ed. 2006, 45, 3782

${ }^{6}$ a) M. Sevilla, A. B. Fuertes. Chem. Eur. J. 2009, 15, 4195 - 4203; b) M. Sevilla, A. B. Fuertes, Carbon, 2009, 47, 2281-2289

${ }^{7}$ a) M.-M. Titirici, M. Antonietti, N. Baccile, Green Chem., 2008, 10, 1204-1212; b) N. Baccile, G. Laurent, F. Babonneau, F. Fayon, M.-M. T., M. Antonietti, J. Phys. Chem. C, 2009, 113, 9644-9654

${ }^{8}$ A. Chuntanapum, Y. Matsumura, Ind. Eng. Chem. Res. 2009, 48, 9837-9846. In this paper, authors study the residual solid product observed from the hydrothermal treatment of hydroxymethylfurfural and refer to it as "tarry material" and not as hydrothermal carbon.

${ }^{9}$ We remind that in SQ-DQ experiments, cross-diagonal peaks identify a correlation between two distinct atomic environments while on-diagonal peaks depict correlation between two atomic environments having the same chemical shift value.

${ }^{10}$ M. M. Tang, R. Bacon, Carbon, 1964, 2, 211-220 
${ }^{11}$ I. Pastorova, R. E. Botto, P. W. Arisz, J. J. Boon, Carbohydr. Res., 1994, 262, 27-47

${ }^{12}$ W. Kolodziejski, J. S. Frye, G. E. Maciel, Anal. Chem., 1982, 54, 1419-1424

${ }^{13}$ J. B. Wooten, J. I. Seeman, M. R. Hajaligol, Energy Fuels, 2004, 18, 1-15

${ }^{14}$ S. Supaluknari, I. Burgar, F. P. Larkins, Org. Geochem., 1990, 15, 509-519

${ }^{15}$ S. Soares, N. M. P. S. Ricardo, S. Jones, F. Heatley, Euro. Polym. J., 2001, 37, 737-745

${ }^{16}$ X. Zhang, J. Golding, I. Burgar, Polymer, 2002, 43, 5791-5796

${ }^{17}$ J. Zawadzki, M. Wisniewski, J. Anal. Appl. Pyrolysis, 2002, 62, 111-121

${ }^{18}$ S. Link, S. Arvelakis, H. Spliethoff, P. De Waard, A. Samoson, Energy Fuels, 2008, 22, 3523-3530

${ }^{19}$ R. K. Sharma, J. B. Wooten, V. L. Balinga, M. R. Hajaligol, Fuel, 2001, 80, 1825-1836

${ }^{20}$ M. Bardet, S. Hediger, G. Gerbaud, S. Gambarelli, J. F. Jacqot, M. F. Foray, A. Gadelle, Fuel, 2007, 86, 1966-1976

${ }^{21}$ V. J. Bartuska, G. E. Maciel, H. I. Bolker, B. I. Fleming, Holzforschung, 1980, 34, 214

${ }^{22}$ H. Wikberg, S. L. Maunu, Carbohydr. Polym., 2004, 58, 461-466

${ }^{23}$ L. Zhao, N. Baccile, S. Gross, Y. Zhang, W. Wei, Y. Sun, M. Antonietti, M.-M. Titirici, Carbon, 2010, 48, 37783787

${ }^{24}$ N. Baccile, M. Antonietti, M.-M. Titirici ChemSusChem 2010, 3, 246 - 253

${ }^{25}$ X. Cao, K. S. Ro, M. Chappell, Y. Li, J. Mao, Energy Fuels, 2011, 25, 388-397

${ }^{26}$ R. M. Davidson, Nuclear Magnetic Resonance Studies of Coal, 1986, IEA Coal Research, London

${ }^{27}$ X. Fang, K. Schmidt-Rohr, J. Agric. Food Chem. 2009, 57, 10701-10711

${ }^{28}$ N. Baccile, G. Laurent, C. Coelho, F. Babonneau, L. Zhao, M.-M. Tititici, Submitted J. Phys. Chem. C, 2011, doi : 10.1021/jp2015512.

${ }^{29}$ R. K. Sharma, J. B. Wooten, V. L. Baliga, P. A. Martoglio-Smith, M. R. Hajaligol, J. Agric. Food Chem. 2002, 50, 771-783

${ }^{30}$ M.J. Antal, G. Varhegyi, E. Jakab, Ind. Eng. Chem. Res., 1998, 37, 1267-1275.

${ }^{31}$ Bennett, A. E.; Rienstra, C. M.; Auger, M; Lakshmi, K. V.; Griffin, R. G. J. Chem. Phys. 1995, 103, 6951

${ }^{32}$ Hediger S.; Meier, B.H.; Kurur, N.D.; Bodenhausen, G.; Ernst, R.R. Chem. Phys. Lett. 1994, 223, 283

${ }^{33}$ Hediger, S.; Meier, B.H.; Ernst, R.R., Chem. Phys. Lett. 1995, 240, 449

${ }^{34}$ Massiot, D.; Fayon, F.; Capron, M.; King, I.; Le Calve, S.; Alonso, B.; Durand, J.-O.; Bujoli, B.; Gan, Z.; Hoatson, G. Magn. Reson. Chem. 2002, 40, 70.

${ }^{35}$ S. J. Opella, M. H. Frey, J. Am. Chem. Soc. 1979, 101, 5854-5856

${ }^{36}$ G. Kresse, J. Hafner, Phys. Rev. B 1994, 49, 14251

${ }^{37}$ H. J. Monkhorst, J. D. Pack, Phys. Rev. B 1976, 13, 5188

${ }^{38}$ P. E. Blöchl, O. Jepsen, O. K. Andersen, Phys. Rev. B 1994, 49, 16223.

${ }^{39}$ P. Giannozzi, S. Baroni, N. Bonini, M. Calandra, R. Car et al. Phys. Cond. Matt. 2009, 21, 395502. 
${ }^{40}$ http://www.pwscf.org; S. Baroni, S. de Gironcoli, A. Dal Corso, and P. Giannozzi, Rev. Mod. Phys., 2001, 73, 515562

${ }^{41}$ C. J. Pickard, F. Mauri Phys. Rev. B, 2001, 63, 245101

${ }^{42}$ C. Gervais, R. Dupree, K. J. Pike, Bonhomme, C.; Profeta, M.; Pickard, C. J.; Mauri, F. J. Phys. Chem. A 2005, 106, 6960.

${ }^{43}$ C. Gervais, C. Coelho, T. Azais, J. Maquet, G. Laurent, F. Pourpoint, C. Bonhomme, P. Florian, B. Alonso, G. Guerrero, P. H. Mutin, F. Mauri, J. Magn. Res., 2007, 187, 131-140.

${ }^{44}$ a) K. Lourvanij, G. L. Rorrer, Appl. Catal. A 1994, 109, 147; b) K. Lourvanij, G. L. Rorrer, Ind. Eng. Chem. Res. 1993, 32, 11; c) M. J. Antal, W. S. L. Mok, G. N. Richards, Carbohyd. Res. 1990, 199, 91

${ }^{45}$ G. R. Hatfield, G. E. Maciel, O. Erbatur, G. Erbatur, Anal. Chem., 1987, 59, 172-179

${ }^{46}$ I.-S. Chuang, G. E. Maciel, G. E. Myers, Macromolecules, 1984, 17, 1087-1090

${ }^{47}$ A. H. Fawcett, A. E. Surgenor, Z. Bashir, R. E. Litchfield, N. G. Todd, Polymer, 1992, 33, 5282-5293

${ }^{48}$ E. B. Sanders, A. I. Goldsmith, J. I. Seeman, J. Anal. Appl. Pyrolysis, 2003, 66, 29-50

${ }^{49}$ C. Falco, N. Baccile, M.-M. Titirici, Green Chem., 2011, DOI: 10.1039/C1GC15742F

${ }^{50}$ M. S. Solum, R. J. Pugmire, D. M. Grant, Energy Fuels, 1989, 3, 187-193

${ }^{51}$ L. dela Rosa, M. Pruski, D. Lang, B. Gernstein, Energy Fuels, 6, 460-468

${ }^{52}$ B. Milsch, W. Windsch, H. Heinzelmann, Carbon, 1968, 6, 807-812

${ }^{53}$ R. Wind, L. Li, G. Maciel, J. Wooten, Appl. Magn. Reson., 1993, 5, 161-176

${ }^{54}$ A. Gandini, M. N. Belgacem, Prog. Polym. Sci., 1997, 22,1203-1379

${ }^{55}$ M. Choura, N. M. Belgacem, A. Gandini, Macromolecules, 1996, 29, 3839-3850

${ }^{56}$ G. C.A. Luijkx, F. van Rantwijk, H. van Bekkum, Carbohyd. Res., 1993, 242, 131-139

${ }^{57}$ A. Kruse, A. Gawlik, Ind. Eng. Chem. Res. 2003, 42, 267. 